INTERNATIONAL JOURNAL OF RESEARCHES IN BIOSCIENCES, AGRICULTURE AND TECHNOLOGY (C) VISHWASHANTI MULTIPURPOSE SOCIETY (Global Peace Multipurpose Society) R. No. MH-659/13(N) www.vmsindia.org

\title{
DISTURBED REDOX BALANCE- A POSSIBLE RISK FACTOR IN PROGRESSION OF PCOS TO NAFLD IN INDIAN WOMEN
}

\author{
P. Mahatme ${ }^{1}$, I. Apte ${ }^{2}$ and S. Kotwal ${ }^{1}$ \\ ${ }^{1}$ University Department of Biochemistry, RTM Napur University, Nagpur, Maharashtra, India-440033. \\ ${ }^{2}$ Department of Biochemistry, IGMC, Nagpur, Maharashtra, India-440018
}

\begin{abstract}
One of the most common infertility disorders in women with ancient records is polycystic ovary syndrome (PCOS). PCOS is a multifaceted, complex condition which apart from infertility might often accompany abnormalities like insulin resistance (IR), Obesity, predisposition to Cardiovascular disease (CVD), Hypertension, Type 2 diabetes mellitus (T2DM), Dyslipidemia, non-alcoholic fatty liver disease (NAFLD) and overall metabolic dysfunction. The definite route behind prevalence of these disorders in women suffering from PCOS is still unclear. The present study attempts to investigate prevalence of oxidative stress in women of reproductive age suffering from PCOS and NAFLD, confined to central India population. We here conclusively demonstrate through biochemical and metabolic evaluation of enrolled patient population that oxidative stress could be a risk factor responsible for progression of PCOS into NAFLD in women of reproductive age. Compared with age, weight and BMI matched 47 healthy women volunteers, 63 PCOS and 51 NAFLD subjects demonstrated a significantly altered metabolic, hormonal and redox balance. PCOS and NAFLD patients showed significantly reduced serum antioxidant capacity through depletion of overall reducing power of serum, decreased glutathione reductase, SOD and CAT levels and elevated lipid peroxides.

Keywords: Polycystic ovary Syndrome, obesity, oxidative stress, SOD, CAT.
\end{abstract}

\section{Introduction}

Polycystic ovary syndrome (PCOS) has gained a worldwide research attention and has been recently given a very germane reference of being the mother of all lifestyle disorders in women (Ganie and Kalra 2011). PCOS is the most common endocrine abnormality in the women of reproductive age and its prevalence has alarmingly raised to almost $12-21 \%$ especially in Australian population (Boyle and Teede 2012) from its previous reported estimate of $4-8 \%$ as per the studies conducted in Greece, Spain and the US (Diamanti-Kandarakis and Dunaif 2012; Azziz 2006). This rapid rise in the occurrence of PCOS is frequently associated with lifestyle modification of women with less physical activities (Norman et al. 2002; Lass et al. 2011; Moran et al. 2006). However, the fact for concern in present scenario is to understand the molecular mechanisms responsible for the manifestation of all the PCOS associated metabolic alterations. PCOS condition in women if unattended not only leads to infertility but often accompanies abnormalities like insulin resistance (IR), Obesity, predisposition to Cardiovascular disease (CVD), Hypertension, Type 2 diabetes mellitus (T2DM), Dyslipidemia, nonalcoholic fatty liver disease (NAFLD) and overall metabolic dysfunction (de Groot et al. 2011; Ovalle and Azziz 2002; Rader 2007; Wild et al. 2010; Kahn et al. 2006). Each of aforementioned disease conditions may have their own serious multifaceted medical implications. This very fact adds ambiguity in determining precise diagnostic parameters for PCOS (Belosi et al. 2006). Furthermore, whether, PCOS is responsible for the development of above mentioned disorders or any of these is the central player needs to be further investigated. One of the less explored but frequented condition with PCOS is NAFLD (Cerda et al. 2007). Patients with aggravated PCOS condition are often found to develop a more serious metabolic dysregulation referred as NAFLD - a hepatic manifestation of metabolic syndrome (Gutierrez-Grobe et al. 2010; Brzozowska et al. 2009). NAFLD represents a spectrum of liver disease ranging from reversible hepatic steatosis, to non alcoholic steatohepatitis (NASH) and cirrhosis with characteristic accumulation of fats in hepatocytes (Ahmed et al. 2012). The present study describes an attempt to elucidate metabolic markers common to PCOS and NAFLD in women of reproductive age.

\section{Material and Methods: Patient population}

The study was reviewed and approved by Institutional Ethics Committee. One hundred and fifty-eight non-pregnant women younger than 36 years of age demonstrating primary infertility were initially enrolled on the basis of one or more following signs like oligomenorrhea, hirsutism, or acne. Cases with severe endometriosis $(n=3)$, Uterine Leiomyomata $(n=4)$, history of previous hypo/hyperthyroidism $(n=6)$, baseline (day 2) $\mathrm{FSH}>12 \mathrm{mIU} / \mathrm{ml}(\mathrm{n}=3)$, or T2DM $(n=28)$ were excluded. The remaining women diagnosed with PCOS $(n=114)$ were included in the study. The diagnosis of PCOS was based on 
the presence of two out of the following three features:

1. Chronic anovulation/oligomenorrhea,

2. Biochemical hyperandrogenemia and

3. Polycystic ovary morphology ( $>12$ follicles) on ultrasound.

Other common causes of

hyperandrogenism (prolactinoma, congenital adrenal hyperplasia, Cushing syndrome, and virilizing ovarian/adrenal tumors) were excluded in accordance with the criteria proposed in 2003 by the Rotterdam ESHRE/ASRM sponsored PCOS Consensus Workshop Group (The Rotterdam ESHRE/ASRM sponsored PCOS consensus workshop group. 2004) with consideration of all the recent revisions incorporated by AE-PCOS Society (Azziz et al. 2006; Azziz et al. 2009). All the enrolled subjects were otherwise healthy, euthyroid, and had normal renal function as demonstrated by normal creatinine clearance values.

Women with PCOS were sub-classified into two groups on the basis of NAFLD condition. Women with a history of chronic viral hepatitis, hemochromatosis, autoimmune liver disease, other chronic liver disease, or those taking hepatotoxic drugs were excluded. Fatty liver was diagnosed by abdominal ultrasound using standardized criteria (Cerda et al. 2007; Neuschwander-Tetri and Caldwell 2003). The first group comprised women who demonstrated only polycystic ovary morphology $(n=63)$ with normal liver while the other demonstrated polycystic ovary with NAFLD (n=51; Fig. 2.1). Forty-seven, age- and weight-matched control women having their infertility attributed to male factors and otherwise healthy were selected as the control group. They had normal ovulatory cycles of $28 \pm 2$ (mean $\pm \mathrm{SD}$ ) days and normal ovarian morphology on ultrasound. Controls had no signs of hyperandrogenism and none of the women studied had galactorrhea or any systemic disease that could possibly influence their reproductive physiology. Furthermore, no women reported use of any medication that could possibly alter their hypothalamicpituitary-gonadal axis. All subjects gave fully informed consent.

\section{Anthropometric indices and Biochemical analysis}

Anthropometric indices viz. Age (years), Weight $(\mathrm{Kg})$, waist circumference, Body Mass Index (BMI) $\left(\mathrm{Kg} / \mathrm{m}^{2}\right)$, Blood Pressure and waistto-hip ratio $(\mathrm{W} / \mathrm{H})$ of the subjects from the three groups (viz. PCOS, PCOS-NAFLD and Control) were recorded at the time of their enrollment in the study. Fasting plasma glucose levels of all the subjects were determined in triplicates with an autoanalyzer. Serum Insulin, LH, FSH, TSH, total testosterone and T4 levels were determined by standard immunoradiometric assays using respective IRMA kits (BECKMAN-COULTER, Cat. \# IM3210, Cat. \# IM 1381, Cat. \# IM 2125, Cat. \# IM 3712 and SIEMENS, Cat \# TKTT1, Cat \# TKT41). The radioactivity was determined in an I-125 Gamma Counter, IC 4702A, Electronic Corporation of India Ltd. (Courtesy, Pitale Diabetes \& Hormone Centre, Nagpur, Maharashtra, India).

Total serum cholesterol was estimated by Innoline TM Cholesterol kit (Merck, India, Ltd., Cat. \# 61909200011730) based on the method detailed previously by Allain et. al. 1974 (Allain et al. 1974). LDL cholesterol levels were estimated by using LDL Cholesterol Colorimetric kit (Labkit, Chemelex, S.A., Merck, Barcelona, Spain, Cat. \# 30185) based on the method described by Okada et. al., 1998 (Okada et al. 1998). The enzymatic determination of serum triglycerides was performed using an Innoline ${ }^{\mathrm{TM}}$ Triglyceride kit (Merck, India, Ltd., Cat. \# 61909700011730) based on the procedure previously described by Fossati et. al. 1982 (Fossati and Prencipe 1982). HDL Cholesterol levels were determined by reverse Friedewald equation.

Biochemical evaluation of liver function was done by determining Alanine aminotransferase (ALT) and Alkaline Phosphatase activity in serum sample of the subjects. Alanine aminotransferase (ALT) activity was estimated in the serum samples by ALT or SGPT activity assay kit (GenWay Biotech, Inc. San Diego, USA, Cat \# GWB-AXR344) according to manufacturer's instructions. Serum Alkaline phosphatase activity was determined by using Alkaline phosphatase activity colorimetric assay kit (BioVision Inc., USA, Cat \#K412-500). Total and direct bilirubin was also estimated in the serum samples by modified Jendrassik and Grof Method, as described by Mori et. al. (Mori 1978) using a Bilirubin estimation kit (Reckon Diagnostic, Pvt. Ltd., Vadodara, India) to assess liver damage.

\section{Serum redox status analysis}

The total reducing (antioxidant) power of the serum samples was determined colorimetrically according to the method of Oyaizu detailed elsewhere (Liu et al. 2008). Serum superoxide dismutase radical scavenging activity was determined by the Nitroblue tetrazolium (NBT) photoreduction method (Beauchamp and Fridovich 1971; Flohe and Otting 1983). Serum catalase activity was 
estimated as described previously (Samy et al. 2006) and Glutathione reductase (GR) activity was determined according to the method detailed by Mavis and Stellwagen (Mavis and Stellwagen 1968).

Serum lipid peroxide (LPx) levels were measured by thiobarbituric acid (TBA) reactivity or the extent of thiobarbituric acid reacting substances (TBARS) in serum as described by Wade and van Rij (Wade and van Rij 1988) and detailed by Bessler et. al. (Besler et al. 2002) with a little modification. Briefly, $200 \mu$ of trichloroacetic acid (TCA) (25 g \%) was added to $1 \mathrm{ml}$ of (1:5 diluted) serum. The mixture was centrifuged at $1000 \mathrm{~g}$ for $10 \mathrm{~min}$, and the precipitate was reacted with $1 \mathrm{ml}$ of $0.67 \%$ TBA (w/v in $2.5 \mathrm{~N} \mathrm{HCl}$ ). The samples were heated at $100^{\circ} \mathrm{C}$ for $30 \mathrm{~min}$. After centrifugation, the absorption of malondialdehyde (MDA)-TBA chromogen was measured at $532 \mathrm{~nm}$. MDA equivalents of the sample were calculated using the extinction coefficient of $1.56 \times 10^{5} \mathrm{M}^{-1} \mathrm{~cm}^{-1}$.

\section{Results and Discussion: \\ Anthropometric indices, IR and hormonal profile}

The anthropometric, basal hormonal features and serum lipid profile of the study enrolled subjects belonging to three groups are summarized in Table 1 . No significant difference was recorded in general anthropometric indices of the study enrolled subjects with an exception of significantly higher BMI values $(P=0.018)$ noted in case of PCOS-NAFLD group. The fasting blood glucose values were also found to differ significantly only in the NAFLD group compared with control $(P=0.018)$. Fasting levels of Insulin were however found to be significantly elevated in both the study groups $(P \leq 0.001)$ as compared to control. Hyperinsulineamia was evident in both the groups but for proper analysis of propensity of insulin resistant within the subjects, HOMA-IR calculations were done according to the following formula:

HOMA1-IR $=[$ Fasting Insulin $(\mathrm{mU} / \mathrm{L}) \times$ Fasting Glucose (mg/dL)] / 405

Because a feedback loop between the liver and beta-cells balances insulin secretion and hepatic glucose output, theoretically, it makes it possible to compute steady-state insulin and glucose concentrations, described as per the original model proposed first in 1985 (Matthews, Hosker et al. 1985). The original model was calibrated to give normal beta-cell function of $100 \%$ and normal insulin resistance of 1 . Higher insulin resistance is characterized by higher steady state insulin levels and reduced beta-cell function characterized by a decreased compensation to increase glucose levels. But the original model did not account for differences between hepatic and peripheral insulin sensitivity, increases in insulin secretion or decreases in hepatic glucose production for plasma glucose concentrations above 180 $\mathrm{mg} / \mathrm{dL}$, renal glucose losses, or the contribution of circulating proinsulin (Wallace et al. 2004; Muniyappa et al. 2008). An updated HOMA model (HOMA2) has since been created, however it is a computer model and has no simple equation but it adjusted to account for these variations. It models insulin sensitivity (HOMA2$\% \mathrm{~S})$ where $100 \%$ is normal which is the reciprocal of insulin resistance $(100 / \mathrm{S} \%)$ as well as can be extrapolated for assessing beta-cell function (\%B). Therefore, HOMA 2 calculation program was downloaded to estimate and reach to a more authentic measure for estimation of IR within the study groups. This program was freely available at http: / / www.dtu.ox.ac.uk/index.php?maindoc=/ homa/. Indeed this updated surrogate indicator of IR gave a more precise difference between the study groups and the control as indicated by increased level of significance (Figure 1 B). Additionally, an indicator for beta-cell function (HOMA 2\% B) showed a compensatory significant elevation in beta-cell function in PCOS group, however although moderately higher but insignificant elevation could be noted in PCOSNAFLD group in comparison to the normal control. With significantly higher indication of IR in PCOS and NAFLD groups a corresponding decrease in sensitivity to insulin was also evident through HOMA $2 \% \mathrm{~S}$ calculations (Figure 1 A). $77.27 \%$ subjects from PCOS group and 90.9\% subjects from PCOS-NAFLD group demonstrated higher IR propensity as per the HOMA2-IR model where individuals falling below the value of 2.1 were considered noninsulin resistant.

Serum levels of gonadotropins (LH and $\mathrm{FSH}$ ), testosterone and T4 and TSH were found to be altered in the study groups. Especially $\mathrm{LH}$ $(P \leq 0.001)$, Testosterone $(P \leq 0.001)$ and T4 $(P$ $=0.006$ ) demonstrated marked elevation in serum samples of PCOS-NAFLD group wherein exhibiting marked and significant elevation in both the study groups in comparison to the control. FSH and TSH did not demonstrate any significant change in the study groups when compared to normal controls (Figure $1 \mathrm{C}$ ).

\section{Serum Lipid Profile}

Serum lipid profile is primary indicator of dislipidemia, commonly observed in several 
metabolic syndromes including PCOS as well as NAFLD. Significantly elevated serum cholesterol $(P \leq 0.001)$ and LDL levels $(P \leq 0.001)$ were prominently observed only in PCOS-NAFLD group. Serum triglyceride levels although higher in this group were not found to be significantly different from the normal controls. The subjects of PCOS group however, did not give any significant indication towards dislipidemic state (Figure 2) as detailed in Table 1.

\section{Liver function test}

Normal hepatocyte functioning was judged through analysis of serum markers of liver function viz. Serum bilirubin (Indirect, Direct and Total) and two major liver associated enzymes SGPT/ALT and Alkaline Phosphatase. The levels of all the three bilirubin values were found to be depleted significantly in both the study groups compared to normal (Figure $3 \mathrm{~B}$ ). However the drop in the values of serum bilirubin was more pronounced in the PCOS group than the NAFLD group. Interestingly, serum albumin levels showed a moderate yet significant drop only in NAFLD group compared to normal controls. A noticeable and significant increase in the activity of ALP in serum sample of patients from PCOS $(P=0.019)$ as well as NAFLD groups $(P \leq 0.001)$ was observed hinting some hepatic damage or plausible onset of steatosis of liver (Figure $3 \mathrm{~A}$ ). A more authentic parameter of liver damage viz. SGPT/ALT activity was found to be significantly elevated only in NAFLD group $(P=0.012)$ indicating serious inclination towards liver damage and probable progression towards NASH.

Other general serum parameters although not associated with liver function were also analyzed, viz. total serum protein which was essential for determining specific activity of certain serum enzymes, serum uric acid because of its recently documented antioxidant properties and serum Creatinine. Although just below the normal range, a significant drop in serum creatinine levels was recorded for NAFLD subjects. Apart creatinine none of the above mentioned general serum parameters were found to demonstrate significant variability in the study groups as compared to that in normal subjects.

\section{Analysis of redox status:}

Complete antioxidant status of the serum was reflected by a unique antioxidant/reducing power assay which was standardized against Glutathione standards. The serum samples collected from patients demonstrated a remarkable depletion in their antioxidant power as compared to that of the normal subjects. This assay thus gave a holistic representation of significantly depressed antioxidant power of serum from both PCOS $(P \leq$ $0.001)$ and the NAFLD group $(P \leq 0.001)$. This result gave an indirect proof of enhanced unattended oxidant levels in serum. This was presumption was further confirmed through detection of serum LPx levels. Validating our presumption the serum LPx levels were found to be drastically elevated in PCOS $(P \leq 0.001)$ as well as the NAFLD $(P \leq 0.001)$ groups as compared to healthy controls. The overall redox balance thus appeared to be severely altered in both the study groups. For further critical evaluation, alteration in the activity of some routinely addressed antioxidant enzymes was assessed. Only serum GR activity was found to be significantly elevated in response to the above observed overpowering oxidant levels and that too only in the NAFLD group $(P=0.002)$. However, CAT activity was found to progressively decrease from PCOS $(P \leq 0.001)$ to NAFLD group $(P \leq 0.001)$. Surprisingly, although SOD activity was found to be significantly reduced in NAFLD $(P \leq 0.001)$ group, a moderate, insignificant elevation in the same was observed in the PCOS group in comparison to control (Figure $3 \mathrm{C}$ ).

The subjects included in the study were enrolled only after recommendation by practicing endocrinologist and were subclassified after confirmed indications of fatty liver condition diagnosed by experienced radiologist. Anthropometric indices of every enrolled subject were recorded to select age and BMI matched normal healthy controls. Waist to height ratio, a parameter considered superior to BMI in some recent articles was also recorded without any significant difference between the three study groups. Waist circumference as a measure of central obesity did seem to demonstrate some variation in PCOS-NAFLD group as compared to the control. Basic serum parameters like fasting glucose and insulin concentrations were determined to calculate the homeostatic model assessment of insulin resistance (HOMA-IR) of the study participants as proposed by Matthews et.al. (Matthews et al. 1985). Considering the limitations of the old HOMA1 model, to account for differences between hepatic and peripheral insulin sensitivity, increases in insulin secretion or decreases in hepatic glucose production for plasma glucose concentrations above 180 $\mathrm{mg} / \mathrm{dL}$, renal glucose losses, or the contribution of circulating proinsulin, a more sensitive and updated HOMA model (HOMA2) was also 
utilized (Wallace et al. 2004). A computer model (http://www.dtu.ox.ac.uk) was used not only to calculate the index of IR (HOMA2-IR) but also to get an insight about approximate beta cell functionality based on values of HOMA2 \% B and insulin sensitivity (HOMA2 \% S). Results obtained in present study once again demonstrated the superiority of the updated HOMA2 model over previously proposed HOMA1 index system (Figure $1 \mathrm{~A} \& \mathrm{~B}$ ) and corroborated the results of earlier investigations (Wallace et al. 2004; Safar et al. 2011).

Endocrinal health of the enrolled subjects was assessed based on their serum hormonal profiles. Considering the correlation of PCOS with reproductive health, the serum levels of LH and FSH were determined on the appropriate day of the cycle. Testosterone levels served as a marker for ascertaining the occurrence of hyperandrogenaemia, while levels of T4 and TSH ensured the euthyroidal status of the subjects. An interesting orchestration of $\mathrm{LH}$ and FSH in theca and granulosa cells of ovaries respectively, dictates the conversion of cholesterol into androstenedione in theca cells which is further converted to estradiol in granulosa cells. Granulosa cells which otherwise have very feeble levels of $\mathrm{LH}$ receptors (LHR), during preovulatory stages are demonstrated to upregulate the expression of LHR under the influence of FSH (Jeppesen et al. 2012). This makes the granulosa cells responsive to elevated LH levels during LH surge thereby leading to their terminal differentiation/leutinization forming corpus luteum, which is composed of both granulosa as well as theca cells, principally producing progesterone. In our study a marginal, yet significantly elevated serum testosterone (Figure $1 \mathrm{C}$ ) level in both PCOS and PCOS-NAFLD groups compared to the control group of healthy subjects indicate towards probable alteration of granulosa cell function or perhaps their aromatase activity (Magoffin 2007; Magoffin et al. 1996). Feedback inhibition elicited by accumulation of this unattended testosterone may lead to elevation of serum androgens (androstenedione and DHEA) ultimately leading to increased serum cholesterol levels (Figure 2). Another interesting perspective that perhaps shares equal responsibility of the raised serum cholesterol in PCOS and PCOS-NAFLD condition can be due to associated IR and plausible decreased responsiveness of theca cells to $\mathrm{LH}$. The latter supposition might be amenable for the significantly higher LH levels recorded for the PCOS and PCOS-NAFLD groups (Figure $1 \mathrm{C}$ ), without any appreciable or compensatory rise in FSH levels. LH and IGF1/insulin has been demonstrated to act synergistically on the theca cells to promote androgen production (Magoffin and Weitsman 1994, 1993b, a). Perhaps this suspected unresponsiveness of theca cells to LH might be at least in part could account for the frequented IR condition in PCOS and PCOSNAFLD subjects, supposedly to meet the gonadotropin requirement of theca cells through insulin's gonadotropin-like action (Munir et al. 2004). Furthermore, according to a study performed on bovine theca and granulosa cells in vitro, T4 has been shown to elevate the androstenedione production in dose dependent manner in presence of insulin and LH (Spicer et al. 2001). This observation would possibly explain the reason behind the significantly elevated T4 levels recorded in PCOS-NAFLD subjects and their correspondingly raised serum testosterone and lipid profile.

Liver is another principle organ whose altered metabolic status might contribute to overall raised levels of serum cholesterol and ultimately the androgens. Extra mobilization or synthesis of cholesterol is possibly dealt well by the cells of polycystic ovaries which convert it to androgens, thus maintaining the serum cholesterol levels (Figure 2). However, the same does not seem to function well during dysregulated hepatic lipid metabolism as depicted from the serum lipid profiles of both PCOS and PCOS-NAFLD groups. Even the serum markers (SGPT/ALT and Alkaline phosphatase) of hepatocyte function therefore seem to be significantly altered in PCOS-NAFLD condition (Figure $3 \mathrm{~A}$ ). Raised ALT values are perhaps thus used as one of the biochemical prognostic marker for NAFLD condition apart from elevated lipid profile, IR and prior to its confirmation through abdominal ultrasound (Neuschwander-Tetri and Caldwell 2003; Nah and Park 2008). Evaluations of other liver function markers in serum like Albumin and Bilirubin also provided some evidences about probable alteration in hepatocyte functioning during PCOS and NAFLD. Although a modest drop in serum albumin levels was recorded in PCOS-NAFLD subjects, we believe that for establishment of a direct correlation of this serum parameter with NAFLD condition further investigation required (Figure $3 \mathrm{D}$ ). Levels of bilirubin (Indirect, direct and total) on the other hand demonstrated an interesting pattern in all the three test groups (Figure $3 \mathrm{~B}$ ). Recently, increasing body of evidences have suggested inverse association of bilirubin levels with IR, 
T2DM, with prevalence in CVD, metabolic syndrome (Lin et al. 2009; Vitek 2012) and even in NAFLD (Chang et al. 2012). Despite these aforementioned study results one noticeable fact is none of these studies involved women subjects; instead the target group there was either pediatric patients or adult men. The present study is therefore one of its kind demonstrating an inverse relationship of serum bilirubin (Indirect, direct and total) levels with occurrence of PCOS and PCOS-NAFLD in women subjects. Furthermore, our results in women subjects not only corroborate results of earlier study performed in Korean men suffering from NAFLD but also gave a strong and serious directive towards plausible inverse correlation of serum bilirubin with PCOS occurrence. It also perhaps indicated towards a liver metabolic paradigm shift during PCOS hinting towards probable predisposition to NAFLD.

Bilirubin has long been considered as a simple metabolic end product of heme catabolism, however recently several studies have shown some interesting implications of heme metabolism and bilirubin. Increased expression of the enzyme, heme oxygenase, which catalyzes the breakdown of hemoglobin to bilirubin has been demonstrated to be associated with reduced adiposity and improved insulin sensitivity in animal models (Nicolai et al. 2009; Ndisang et al. 2010; Li et al. 2008). Moreover, a direct influence of serum bilirubin levels is predicted in free fatty acid metabolis m (Shepherd et al. 1979) and perhaps even in lipid metabolism. This increased awareness about serum bilirubin could be mainly because of its unique anti-lipolytic activity observed in case of some animal models (Naylor et al. 1980). This anti-lipolytic activity could have great significance since elevated de novo lipogenesis and peripheral fatty acids mainly derived from lipolysis of adipose tissue contribute to the accumulation of hepatic fat in NAFLD. Furthermore, the antioxidant facet and protective function of bilirubin against oxidative stress is also attracting increased scientific attention (Liu et al. 2003; Clark et al. 2000). Considering the massive involvement of oxidative stress in development and pathogenesis of PCOS as well as NAFLD (Brzozowska et al. 2009; Macut et al. 2012; Rezazadeh et al. 2012) serum bilirubin measurements may give some prediction about oxidative status of the subjects. The overall redox status of the study enrolled subjects was also estimated using some authentic oxidation and PCOS-NAFLD (Victor et al. 2011; Fenkci et al. 2003). and antioxidant markers in serum. Lipid peroxidation status of each subject was determined as serum TBARS to get an estimate of oxidative stress. Instead of measuring individual antioxidant concentrations in serum, the total antioxidant capacity of the serum samples was assessed as proposed previously (Benzie and Strain 1996; Liu et al. 2008). The reducing/antioxidant power values thus obtained were represented as equivalent to molar Glutathione concentrations. As is evident from the Figure $3 \mathrm{C}$, a significantly higher level of TBARS and a significant and corresponding depletion in overall antioxidant power of the serum samples was recorded in PCOS and PCOS-NAFLD group in comparison to the normal healthy control subjects. Furthermore, elevation in Glutathione reductase activity was recorded in the PCOS and NAFLD groups, perhaps to compensate for the insufficient antioxidant ability of their serum samples. An interesting noticeable fact here was a significant rise in GR activity was recorded only in PCOSNAFLD group while the PCOS group demonstrated only a modest increase compared to the control. Finally when the serum samples were analyzed for the two most highly regarded antioxidant enzymes CAT and SOD, a minor variation was noticed in the pattern of activity of these two enzymes in the test groups. Whereas CAT showed a statistically significant drop in PCOS and PCOS-NAFLD groups in comparison to the control, SOD activity seemed to be elevated in PCOS group while the same showed a significantly decreased activity in PCOSNAFLD group compared to the control. Some previously conducted studies have also indicated elevated SOD levels in PCOS (Zhang et al. 2008). This most likely, may partly, provide an explanation for the inappropriate and modest rise of GR activity of the PCOS group in spite of considerable drop in the overall antioxidant power of their serum samples. However, the significantly elevated LPx levels do indicate that compensation provided by SOD for GR in PCOS and GR alone in NAFLD group is certainly not sufficient to prevent the abruptly intensified oxidant activities under these conditions. Elevated serum lipid concentrations in PCOS and NAFLD do provide an extra raw material for oxidation and thereby contribute in elevation of serum LPxs (Macut et al. 2012). The results of this study therefore corroborate the observations of some previous studies and do indicate that oxidative stress is more pronounced in subjects suffering from PCOS 
Table No. 1:

\begin{tabular}{|c|c|c|c|c|c|c|c|c|}
\hline \multicolumn{2}{|r|}{ Parameters } & \multicolumn{2}{|c|}{$\begin{array}{c}\text { Control } \\
(n=47)\end{array}$} & \multicolumn{2}{|c|}{$\begin{array}{l}\text { PCOS } \\
(n=63)\end{array}$} & \multicolumn{2}{|c|}{$\begin{array}{c}\text { PCOS +NAFLD } \\
(n=51)\end{array}$} & \multirow{2}{*}{$\frac{P \text { - value }}{0.262}$} \\
\hline \multirow{4}{*}{$\begin{array}{l}\text { Anthropometric } \\
\text { Indices }\end{array}$} & Age (years) & 25.45 & \pm 6.47 & 23.91 & \pm 6.23 & 23.36 & \pm 6.90 & \\
\hline & Waist to Hip Ratio & 0.88 & \pm 0.05 & 0.88 & \pm 0.05 & 0.9 & \pm 0.08 & 0.158 \\
\hline & Waist Circumference $(\mathrm{cm})$ & 97.85 & \pm 9.58 & 95.07 & \pm 11.09 & 100.73 & \pm 9.77 & 0.162 \\
\hline & Body Mass Index $\left(\mathrm{kg} / \mathrm{m}^{2}\right)$ & 29.77 & \pm 5.30 & 28.35 & \pm 4.90 & 32.15 & $\pm 4.65^{*}$ & 0.018 \\
\hline \multirow{12}{*}{$\begin{array}{l}\text { Hormone } \\
\text { And } \\
\text { Metabolic } \\
\text { Profile }\end{array}$} & Fasting Insulin $(\mu \mathrm{IU} / \mathrm{ml})$ & 21.02 & \pm 6.33 & 26.18 & $\pm 6.01^{* * *}$ & 28.09 & $\pm 6.53^{* * *}$ & $\leq 0.001$ \\
\hline & Fasting Glucose (mg/dL) & 83.31 & \pm 5.57 & 83.39 & \pm 8.12 & 88.25 & $\pm 13.06^{*}$ & 0.01 \\
\hline & HOMA-IR & 4.32 & \pm 1.46 & 5.29 & \begin{tabular}{|l|} 
$\pm 1.25^{* *}$ \\
\end{tabular} & 6.25 & $\pm 2.52^{* * *}$ & $\leq 0.001$ \\
\hline & Testosterone (ng/ml) & 0.82 & \pm 0.23 & 1.11 & $\pm 0.22^{* * *}$ & 1.01 & $\pm 0.20^{* * *}$ & $\leq 0.001$ \\
\hline & LH (mIU/ml) & 4.79 & \pm 1.55 & 5.61 & \pm 1.71 & 6.82 & $\pm 3.10^{* * *}$ & $\leq 0.001$ \\
\hline & FSH (mIU/ml) & 3.04 & \pm 1.43 & 3.26 & \pm 1.29 & 3.35 & \pm 1.45 & 0.519 \\
\hline & TSH $(\mathrm{mIU} / \mathrm{ml})$ & 3.15 & \pm 2.50 & 2.63 & \pm 1.16 & 3 & \pm 1.91 & 0.329 \\
\hline & T4 ( $\mu \mathrm{g} / \mathrm{dL})$ & 8.22 & \pm 1.12 & 7.88 & \pm 2.05 & 9.05 & $\pm 0.77^{* * *}$ & 0.006 \\
\hline & Serum Cholesterol (mg/dL) & 149.29 & \pm 14.37 & 146.03 & \pm 17.90 & 160.52 & $\pm 20.04^{* *}$ & 0.002 \\
\hline & HDL (mg/dL) & 38.05 & \pm 1.08 & 38.09 & \pm 1.19 & 37.96 & \pm 0.90 & 0.810 \\
\hline & LDL (mg/dL) & 75.8 & \pm 10.49 & 76.8 & \pm 12.18 & 87.25 & $\pm 18.62^{* * *}$ & $\leq 0.001$ \\
\hline & Serum Triglycerides $(\mathrm{mg} / \mathrm{dL})$ & 146.45 & \pm 23.22 & 143.31 & \pm 32.51 & 152.8 & \pm 48.70 & 0.379 \\
\hline
\end{tabular}

Values are expressed as mean \pm standard deviation $P<0.05^{*} ; P<0.01^{* *} ; P<0.001^{* * *}$ vs Control
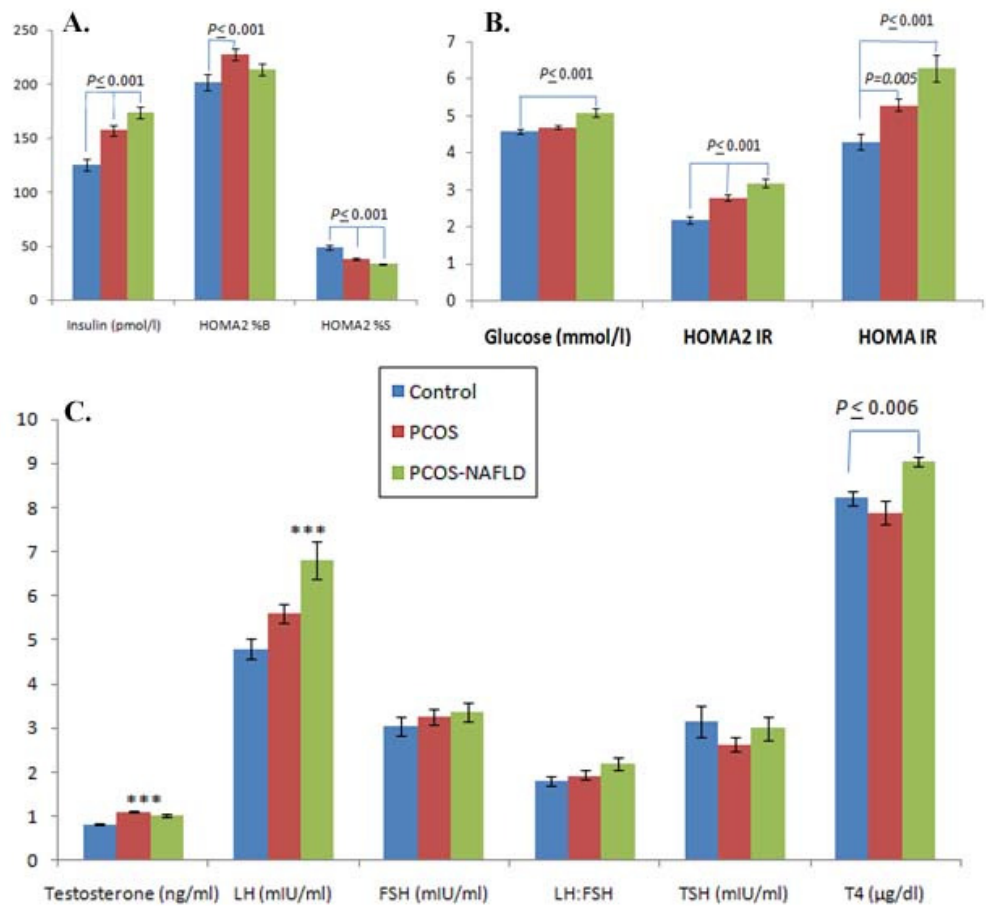

Figure. 1-

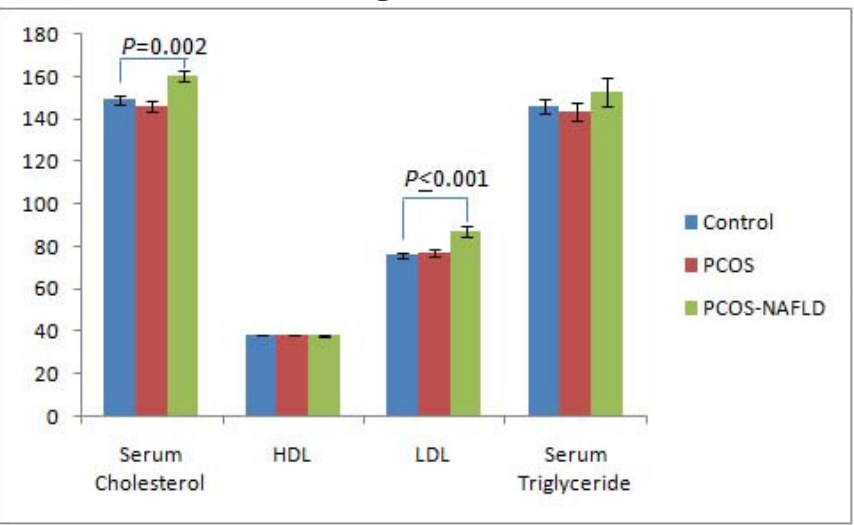

Figure. 2- 


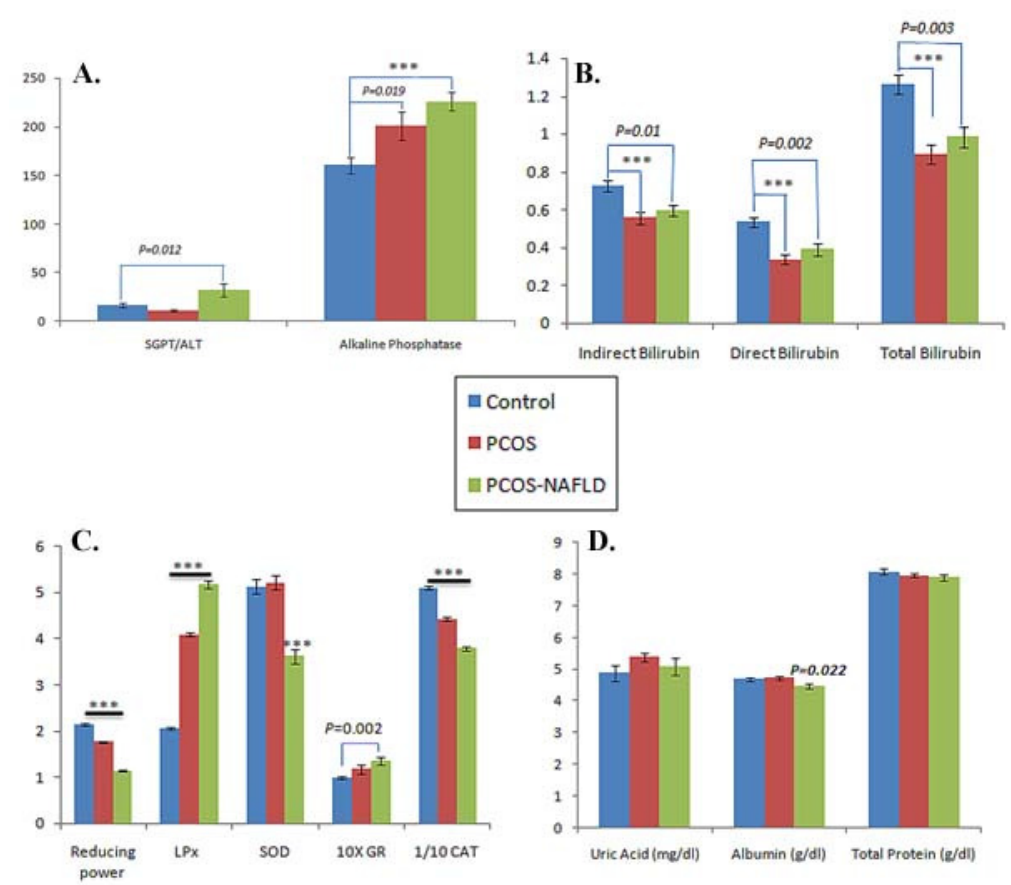

Figure 3

\section{References:}

Ahmed A, Rabbitt E, Brady T, Brown C, Guest P, Bujalska IJ, Doig C, Newsome PN, Hubscher S, Elias E, Adams DH, Tomlinson JW, Stewart PM (2012) A Switch in Hepatic Cortisol Metabolism across the Spectrum of Non Alcoholic Fatty Liver Disease. PLoS ONE 7 (2):e29531

Allain CC, Poon LS, Chan CSG, Richmond W, Fu PC (1974) Enzymatic Determination of Total Serum Cholesterol. Clinical Chemistry 20 (4):470-475

Azziz R (2006) Diagnosis of Polycystic Ovarian Syndrome: The Rotterdam Criteria Are Premature. Journal of Clinical Endocrinology \& Metabolism $\quad 91 \quad$ (3):781-785. doi: $10.1210 /$ jc. 2005-2153

Azziz R, Carmina E, Dewailly D, DiamantiKandarakis E, Escobar-Morreale HF, Futterweit W, Janssen OE, Legro RS, Norman RJ, Taylor AE, Witchel SF (2006) Criteria for Defining Polycystic Ovary Syndrome as a Predominantly Hyperandrogenic Syndrome: An Androgen Excess Society Guideline. Journal of Clinical Endocrinology \& Metabolism 91 (11):4237-4245. doi:10.1210/jc.2006-0178

Azziz R, Carmina E, Dewailly D, DiamantiKandarakis E, Escobar-Morreale HF, Futterweit W, Janssen OE, Legro RS, Norman RJ, Taylor AE, Witchel SF (2009) The Androgen Excess and PCOS Society criteria for the polycystic ovary syndrome: the complete task force report. Fertility and Sterility 91 (2):456-488
Beauchamp C, Fridovich I (1971) Superoxide dismutase: improved assays and an assay applicable to acrylamide gels. Analytical biochemistry 44 (1):276-287

Belosi C, Selvaggi L, Apa $R$, Guido M, Romualdi D, Fulghesu AM, Lanzone A (2006) Is the PCOS diagnosis solved by ESHRE/ASRM 2003 consensus or could it include ultrasound examination of the ovarian stroma? Human Reproduction $\quad 21 \quad$ (12):3108-3115. doi:10.1093/humrep/del306

Benzie IF, Strain J (1996) The ferric reducing ability of plasma (FRAP) as a measure of "antioxidant power": the FRAP assay. Analytical biochemistry 239 (1):70-76

Besler HT, Çomoğlu S, OkÇu Z (2002) Serum levels of antioxidant vitamins and lipid peroxidation in multiple sclerosis. Nutritional neuroscience 5 (3):215-220

Boyle J, Teede HJ (2012) Polycystic ovary syndrome: An update. Australian Family Physician 41 (10):752-756

Brzozowska MM, Ostapowicz G, Weltman MD (2009) An association between non-alcoholic fatty liver disease and polycystic ovarian syndrome. Journal of gastroenterology and hepatology 24 (2):243-247

Cerda C, Pérez-Ayuso RM, Riquelme A, Soza $A$, Villaseca $P$, Petermann $T$, Espinoza $M$, Pizarro M, Solis N, Miquel JF (2007) Nonalcoholic fatty liver disease in women with polycystic ovary syndrome. Journal of hepatology 47 (3):412-417 
Chang Y, Ryu S, Zhang Y, Son HJ, Kim J-Y, Cho J, Guallar E (2012) A Cohort Study of Serum Bilirubin Levels and Incident NonAlcoholic Fatty Liver Disease in Middle Aged Korean Workers. PLoS ONE 7 (5):e37241

Clark J, Foresti R, Green C, Motterlini R (2000) Dynamics of haem oxygenase-1 expression and bilirubin production in cellular protection against oxidative stress. Biochem $\mathrm{J}$ 348:615-619

de Groot PCM, Dekkers OM, Romijn JA, Dieben SWM, Helmerhorst FM (2011) PCOS, coronary heart disease, stroke and the influence of obesity: a systematic review and metaanalysis. Human Reproduction Update 17 (4):495-500. doi:10.1093/humupd/dmr001

Diamanti-Kandarakis E, Dunaif A (2012) Insulin Resistance and the Polycystic Ovary Syndrome Revisited: An Update on Mechanisms and Implications. Endocrine Reviews 33 (6):9811030. doi: $10.1210 /$ er.2011-1034

Fenkci V, Fenkci S, Yilmazer M, Serteser M (2003) Decreased total antioxidant status and increased oxidative stress in women with polycystic ovary syndrome may contribute to the risk of cardiovascular disease. Fertility and Sterility 80 (1):123-127

Flohe L, Otting F (1983) Superoxide dismutase assays. Methods in enzymology 105:93-104

Fossati P, Prencipe L (1982) Serum triglycerides determined colorimetrically with an enzyme that produces hydrogen peroxide. Clinical Chemistry 28 (10):2077-2080

Ganie M, Kalra S (2011) Polycystic ovary syndrome - A metabolic malady, the mother of all lifestyle disorders in women - Can Indian health budget tackle it in future? , vol 15. vol 4 . doi: $10.4103 / 2230-8210.85571$

Gutierrez-Grobe Y, Ponciano-Rodriguez G, Ramos MH, Uribe M, Méndez-Sánchez N (2010) Prevalence of non alcoholic fatty liver disease in premenopausal, posmenopausal and polycystic ovary syndrome women. The role of estrogens. Ann Hepatol 9 (4):402-409

Jeppesen JV, Kristensen SG, Nielsen ME, Humaidan P, Dal Canto M, Fadini R, Schmidt KT, Ernst E, Yding Andersen C (2012) LHreceptor gene expression in human granulosa and cumulus cells from antral and preovulatory follicles. The Journal of Clinical Endocrinology \& Metabolism 97 (8):E1524-E1531

Kahn SE, Hull RL, Utzschneider KM (2006) Mechanisms linking obesity to insulin resistance and type 2 diabetes. Nature 444 (7121):840-846
Lass $\mathbf{N}$, Kleber $\mathbf{M}$, Winkel $\mathbf{K}$, Wunsch $\mathbf{R}$, Reinehr T (2011) Effect of Lifestyle Intervention on Features of Polycystic Ovarian Syndrome, Metabolic Syndrome, and Intima-Media Thickness in Obese Adolescent Girls. The Journal of Clinical Endocrinology \& Metabolism 96 (11):3533-3540. doi:doi:10.1210/jc.20111609

Li M, Kim DH, Tsenovoy PL, Peterson SJ, Rezzani R, Rodella LF, Aronow WS, Ikehara S, Abraham NG (2008) Treatment of obese diabetic mice with a heme oxygenase inducer reduces visceral and subcutaneous adiposity, increases adiponectin levels, and improves insulin sensitivity and glucose tolerance. Diabetes 57 (6):1526-1535

Lin L-Y, Kuo H-K, Hwang J-J, Lai L-P, Chiang F-T, Tseng C-D, Lin J-L (2009) Serum bilirubin is inversely associated with insulin resistance and metabolic syndrome among children and adolescents. Atherosclerosis 203 (2):563-568

Liu $\mathbf{X}$, Zhao M, Wang $J$, Yang $B$, Jiang $\mathbf{Y}$ (2008) Antioxidant activity of methanolic extract of emblica fruit $(<\mathrm{i}>$ Phyllanthus emblica $</ \mathrm{i}>\mathrm{L}$.) from six regions in China. Journal of food composition and Analysis 21 (3):219-228

Liu Y, Zhu B, Wang X, Luo L, Li P, Paty DW, Cynader MS (2003) Bilirubin as a potent antioxidant suppresses experimental autoimmune encephalomyelitis: implications for the role of oxidative stress in the development of multiple sclerosis. Journal of neuroimmunology 139 (1):27-35

Macut D, Bjekić-Macut J, Savić-Radojević A (2012) Dyslipidemia and Oxidative Stress in PCOS.

Magoffin DA (2007) Ovarian Steroidogenic Abnormalities in the Polycystic Ovary Syndrome. In: Androgen Excess Disorders in Women. Springer, pp 203-211

Magoffin DA, Agarwal SK, Jakimiuk AJ (1996) Suppression of Aromatase Activity in Polycystic Ovary Syndrome. In: Polycystic Ovary Syndrome. Springer, pp 208-222

Magoffin DA, Weitsman SR (1993a) Differentiation of ovarian theca-interstitial cells in vitro: regulation of 17 alpha-hydroxylase messenger ribonucleic acid expression by luteinizing hormone and insulin-like growth factor-I. Endocrinology 132 (5):1945-1951

Magoffin DA, Weitsman SR (1993b) Insulinlike growth factor-I stimulates the expression of 3 beta-hydroxysteroid dehydrogenase messenger ribonucleic acid in ovarian theca-interstitial cells. Biology of reproduction 48 (5):1166-1173

Magoffin DA, Weitsman SR (1994) Insulin-like growth factor-I regulation of luteinizing hormone 
(LH) receptor messenger ribonucleic acid expression and LH-stimulated signal transduction in rat ovarian theca-interstitial cells. Biology of reproduction 51 (4):766-775

Matthews D, Hosker J, Rudenski A, Naylor B, Treacher D, Turner $\mathbf{R}$ (1985) Homeostasis model assessment: insulin resistance and $\beta$-cell function from fasting plasma glucose and insulin concentrations in man. Diabetologia 28 (7):412-419

Mavis RD, Stellwagen E (1968) Purification and subunit structure of glutathione reductase from bakers' yeast. Journal of Biological Chemistry 243 (4):809-814

Moran LJ, Brinkworth G, Noakes M, Norman RJ (2006) Effects of lifestyle modification in polycystic ovarian syndrome. Reproductive BioMedicine Online $12 \quad$ (5):569-578. doi:http:/ /dx.doi.org/10.1016/S14726483(10)61182-0

Mori L (1978) Modified Jendrassik--Grof method for bilirubins adapted to the Abbott Bichromatic Analyzer. Clinical Chemistry 24 (10): 1841-1845

Munir I, Yen H-W, Geller DH, Torbati D, Bierden RM, Weitsman SR, Agarwal SK, Magoffin DA (2004) Insulin augmentation of 17a-hydroxylase activity is mediated by phosphatidyl inositol 3-kinase but not extracellular signal-regulated kinase-1/2 in human ovarian theca cells. Endocrinology 145 (1): $175-183$

Muniyappa R, Lee S, Chen H, Quon MJ (2008) Current approaches for assessing insulin sensitivity and resistance in vivo: advantages, limitations, and appropriate usage. American Journal of Physiology-Endocrinology And Metabolism 294 (1):E15-E26

Nah EH, Park JY (2008) Metabolic characteristics and associated factors of nonalcoholic fatty liver disease diagnosed at medical checkups. The Korean journal of laboratory medicine 28 (3):244-250

Naylor JM, Kronfeld DS, Johnson K (1980) Fasting hyperbilirubinemia and its relationship to free fatty acids and triglycerides in the horse. Experimental Biology and Medicine 165 (1):8690

Ndisang JF, Lane N, Syed N, Jadhav A (2010) Up-regulating the heme oxygenase system with hemin improves insulin sensitivity and glucose metabolism in adult spontaneously hypertensive rats. Endocrinology 151 (2):549-560

Neuschwander-Tetri BA, Caldwell SH (2003) Nonalcoholic steatohepatitis: summary of an
AASLD Single Topic Conference. Hepatology 37 (5):1202-1219

Nicolai A, Li M, Kim DH, Peterson SJ, Vanella L, Positano V, Gastaldelli A, Rezzani R, Rodella LF, Drummond G (2009) Heme oxygenase-1 induction remodels adipose tissue and improves insulin sensitivity in obesityinduced diabetic rats. Hypertension 53 (3):508515

Norman RJ, Davies MJ, Lord J, Moran LJ (2002) The role of lifestyle modification in polycystic ovary syndrome. Trends in Endocrinology \& Metabolism 13 (6):251-257. doi:http:/ /dx.doi.org/10.1016/S10432760(02)00612-4

Okada M, Matsui H, Ito Y, Fujiwara A, Inano K (1998) Low-density lipoprotein cholesterol can be chemically measured: a new superior method. Journal of Laboratory and Clinical Medicine 132 (3): 195-201

Ovalle F, Azziz $\mathbf{R}$ (2002) Insulin resistance, polycystic ovary syndrome, and type 2 diabetes mellitus. Fertility and Sterility 77 (6):1095-1105. doi:http:/ /dx.doi.org/10.1016/S00150282(02)03111-4

Rader DJ (2007) Effect of Insulin Resistance, Dyslipidemia, and Intra-abdominal Adiposity on the Development of Cardiovascular Disease and Diabetes Mellitus. The American journal of medicine 120 (3, Supplement 1):S12-S18. doi:http:/ /dx.doi.org/10.1016/j.amjmed.2007.0 1.003

Rezazadeh A, Yazdanparast $\mathbf{R}$, Molaei $\mathbf{M}$ (2012) Amelioration of diet-induced nonalcoholic steatohepatitis in rats by $\mathrm{Mn}$-salen complexes via reduction of oxidative stress. J Biomed Sci 19:26

Safar FH, Mojiminiyi OA, Al-Rumaih HM, Diejomaoh MF (2011) Computational methods are significant determinants of the associations and definitions of insulin resistance using the homeostasis model assessment in women of reproductive age. Clinical Chemistry 57 (2):279285

Samy RP, Gopalakrishnakone $P$, Ignacimuthu S (2006) Anti-tumor promoting potential of luteolin against 7, 12-dimethylbenz $(<\mathrm{i}>\mathrm{a}</ \mathrm{i}>)$ anthracene-induced mammary tumors in rats. Chemico-biological interactions 164 (1):1-14

Shepherd R, Moreno F, Cashore W, Fain $\mathbf{J}$ (1979) Effects of bilirubin on fat cell metabolis m and lipolysis. American Journal of PhysiologyGastrointestinal and Liver Physiology 237 (6):G504-G508

Spicer L, Alonso J, Chamberlain C (2001) Effects of thyroid hormones on bovine granulosa 
and thecal cell function in vitro: dependence on insulin and gonadotropins. Journal of dairy science 84 (5):1069-1076

The Rotterdam ESHRE/ASRM sponsored PCOS consensus workshop group. (2004) Revised 2003 consensus on diagnostic criteria and long-term health risks related to polycystic ovary syndrome (PCOS). Human Reproduction 19 (1):41-47. doi:10.1093/humrep/deh098

Victor VM, Rocha M, Bañuls C, Alvarez A, de Pablo C, Sanchez-Serrano M, Gomez M, Hernandez-Mijares A (2011) Induction of oxidative stress and human leukocyte/endothelial cell interactions in polycystic ovary syndrome patients with insulin resistance. Journal of Clinical Endocrinology \& Metabolism 96 (10):3115-3122

Vitek L (2012) The role of bilirubin in diabetes, metabolic syndrome, and cardiovascular diseases. Frontiers in pharmacology 3

Wade CR, van Rij AM (1988) Plasma thiobarbituric acid reactivity: reaction conditions and the role of iron, antioxidants and lipid peroxy radicals on the quantitation of plasma lipid peroxides. Life sciences 43 (13):1085-1093
Wallace TM, Levy JC, Matthews DR (2004) Use and abuse of HOMA modeling. Diabetes care 27 (6): 1487-1495

Wild RA, Carmina E, Diamanti-Kandarakis E, Dokras A, Escobar-Morreale HF, Futterweit W, Lobo R, Norman RJ, Talbott E, Dumesic DA (2010) Assessment of Cardiovascular Risk and Prevention of Cardiovascular Disease in Women with the Polycystic Ovary Syndrome: A Consensus Statement by the Androgen Excess and Polycystic Ovary Syndrome (AE-PCOS) Society. The Journal of Clinical Endocrinology \& Metabolism $95 \quad$ (5):2038-2049. doi:doi: 10.1210/jc.2009-2724

Zhang $D$, Luo $W$, Liao $H$, Wang $C$, Sun $Y$ (2008) The effects of oxidative stress to PCOS. Sichuan da xue xue bao Yi xue ban= Journal of Sichuan University Medical science edition 39 (3):421-423 